Published as: Van De Vijver, E., Derudder, B., O'Connor, K., Witlox, F. (2016). Shifting patterns and determinants of Asia-Pacific tourism to Australia, 1990-2010. Asia Pacific Journal of Tourism Research, vol. 21 (12), pp. 1357-1372.

\title{
Shifting patterns and determinants of Asia-Pacific tourism to Australia, 1990-2010
}

\author{
Elien Van De Vijver \\ Elien.VanDeVijver@ugent.be \\ T. +3292644555 \\ F. +3292644985
}

Ben Derudder ${ }^{\mathrm{a}}$ (corresponding author)

Ben.Derudder@ugent.be

T. +3292644556

F. +3292644985

Kevin O'Connor ${ }^{b}$

Kevin.oconnor@unimelb.edu.au

T. +613-8344 7474

F. $+613-8344-5532$

Frank Witlox ${ }^{\mathrm{a}}$

Frank.Witlox@ugent.be

T. +3292644553

F. +3292644985

${ }^{a}$ Department of Geography, Ghent University, Krijgslaan 281/S8, B9000 Gent, Belgium

${ }^{b}$ Department of Urban Planning, Faculty of Architecture, Building and Planning, University of Melbourne, Parkville 3101, Australia

\footnotetext{
Abstract

Australia is a major international holiday destination, with growing numbers of tourists each year. Especially travel demand from Asia-Pacific countries has increased in the period between 1990 and 2010, which has led Australian policy-makers to believe the Asia-Pacific region will be the largest growth market for holiday tourists over the next years. This research note explores the major
} 
determinants underlying the shifting geographical patterns of Asia-Pacific tourism to Australia. Results indicate that economic growth remains the most important factor explaining tourism demand. Its high, but declining, impact suggests that countries with higher per capita income produce higher levels of tourism towards Australia, but that the Australian holiday market is becoming increasingly mature. As a consequence, further 'organic' growth of tourism because of expected income growth in Asia-Pacific cannot simply be assumed. Distance, as a proxy for travel costs, has large negative elasticity that has slightly increased over time. We consider two major forces that have influenced this variable: air transport liberalization reduces 'distance', but these effects have been off-set by oil prices, which increase 'distance'. The latter could impose an impediment to future tourism growth, especially if liberalization in Asia-Pacific region is delayed.

Keywords: Air transport, Asia-Pacific, Australia, income, distance, population, tourism, travel demand, air transport liberalization, fuel price

\section{Introduction}

Tourism is a crucial industry for the Australian economy: in 2012-2013, tourism accounted for $6 \%$ of total GDP and 8\% of Australia's employment (Kookana et al., 2014). Data from the Australian Bureau of Statistics reveal that the total volume of air travel to Australia - most of which is tourism-related has risen about fivefold between 1985 and 2010: whereas about 2.809.700 passengers arrived in 1985, this volume grew to 14.221 .700 in 2010. O'Connor and Fuellhart (2014) have shown that in this period the Asia-Pacific region has become the main international aviation market for Australian cities, surpassing the traditional European and North American routes.

Given Asia-Pacific's growing importance, the Australian government tries to monitor and stimulate tourism in several ways. Within the context of the National Long-Term Tourism Strategy, Tourism Australia - the government agency responsible for promoting Australia as a destination for business and leisure travel - has launched the 'Tourism 2020 Strategy'. In this strategy, growth and competitiveness of the tourism industry is sought by focusing on six strategic areas. One major strategic area is to 'Grow demand from Asia', which reflects the emerging importance of this region as a source market for tourism to Australia: between 2010 and 2020, Asia is expected to contribute more than half of the projected growth in international visitors, with especially China assuming a central place in the Australian strategy as it is expected to produce 42 percent of the growth (Tourism Australia, 2011). The emerging focus on Asia-Pacific is also reflected in the way in which Tourism Australia organizes its global marketing strategy. To promote 'Tourism 2020' internationally, the agency focuses the majority of its global marketing resources on those markets representing the greatest potential for tourism growth over the next few years. Whereas the Americas and Europe are seen as two large, but largely stable and homogenous markets, the Asian market receives a more differentiated treatment. Greater China (China and Hong Kong) is thought to form a separate market, as are Japan and Korea. Other specific markets in the region are New Zealand, South Asia, and Southeast Asia. 
Although some of the geographical differentiation in the approach of the Asia-Pacific market may simply reflect differences in distance and cultural heterogeneity, it is likely that it above all reveals a shift in strategy where fast-growing markets receive extra attention. This becomes clear when looking at the shifting geographies of tourism within Asia-Pacific (Table 1). For instance, although New Zealand and Japan remain Australia's largest source markets, there has been a rather dramatic drop in Japanese tourist from the end of the 1990s onwards, which partly reflects the ongoing stagnation of the Japanese economy. This is in sharp contrast with the volume of Chinese tourists, which has exploded over the last 20 years, currently making China the third largest market of AsiaPacific tourists. South Korea, Hong Kong, Thailand, and Taiwan and Indonesia and Singapore have also become major markets in line with their economic growth spurts, while countries Sri Lanka, Laos, and Cambodia remain smaller markets.

The increasing importance of, and the shifting patterns within Asia-Pacific as a source market for tourism to Australia raises a number of research questions. Continuing and extending the journal's interest in tourism (Baldacchino, 2006; McElroy, 2006; McElroy \& Hamma, 2010; Pearce, 2001; Scheyvens, 2011), in this research note, we focus on a research question that is pertinent for tourism policy: what are the main factors that have been driving the changing demand for Asia-Pacific tourism to Australia? 


\section{Data and methodology}

In this research note, we define tourists as those passengers arriving in Australia with the prime purpose of spending their holiday. We use information from incoming air passengers from 22 AsiaPacific countries, as collected by the Australian Department of Immigration and Citizenship ${ }^{1}$. We only focus on those passenger cards that mention holiday arrival as the primary purpose for visiting.

The potential factors influencing the geographies of tourism to Australia are, of course, likely to be both varied and complex (Crouch, 1994; Lim, 1999; Seetaram, 2012), and may include a range of tacit factors such as cultural proximity. For instance, the relative social and mental proximity and large cross-migration between New Zealand and Australia leads to strong air travel connections because of myriad cultural exchanges in the broadest sense, enhanced knowledge about leisure and business opportunities that are furthermore facilitated because of the shared language, visiting friends and relatives that have migrated, etc. However, as such processes are very hard to systematically operationalize and interpret, here we focus on three key straightforward indicators derived from the air travel demand literature. Gillen (2010) suggests that, in addition to (1) the obvious effect of population size (operationalized here based on data provided by Asian Development Bank), demand for air travel (business and leisure alike) - is primarily influenced by:

(2) Macro-economic forces such as gross domestic product (GDP) and trade (e.g. the stagnation of tourism from Japan in the face of rising volumes of tourists from China). In our model we use GDP per capita at purchasing power parity (derived from the International Monetary Fund, and supplemented with data from the World Bank for Macau);

(3) Geographic proximity: shorter distances generally lead to more demand for air travel, primarily because the costs for making the air transport connection become smaller (e.g. the larger volumes of tourists from New Zealand than from India), albeit that the relation between distance and cost is imperfect. In our model we use measures derived from the CEPII-database. This is a calculation based upon the distance between the largest cities (in population numbers) of any pair of countries. The inter-city distances are then weighted by the share of each city in the overall country's population (Mayer \& Zignago, 2011).

We estimate the volume of Asia-Pacific tourism to Australia using multiple linear regressions with GDP per capita, population and distance as independent variables and the number of tourists ad the dependent variable. We do this for three different moments in time $(1990,2000$, and 2010) in order to evaluate the changing role and effect of the three different explanatory variables throughout this time period. Importantly, studying the period between 1990 and 2010 through 10-year intervals allows us to monitor changes in the absolute and relative importance of these factors: shifting absolute importance will be gauged through unstandardized beta coefficients, which can be interpreted as elasticities (e.g. assessing the changing absolute importance of distance in the face of changes in the air transport market); shifting relative importance will be gauged through standardized beta coefficients (e.g. assessing the changing relative importance of distance compared

\footnotetext{
${ }^{1}$ The empirics used in this paper thus exclusively focus on international tourists arriving by air, but given Australia's geography this captures over 99 per cent of all international visitors.
} 
to the other variables). Nonetheless, in spite of changes in the absolute and relative importance of these variables, their combined explanatory power remains high (each of the models explains more than $90 \%$ of the variation in Asia-Pacific's tourism geographies to Australia), which corroborates our focus on this limited set of straightforward indicators. Although forecasting in the strict sense is very difficult given the changing importance of these factors over time, our results allow formulating a number of anticipated changes and associated suggestions for Australian tourism policy.

Because we work with a small sample of 22 observations for each year, and because the assumptions of linear regression were not always fulfilled (non-normal distribution of residuals, and signs of heteroskedasticity) for every year, we applied the method of bootstrapping to check the robustness of our results (Efron, 1979). We used random resampling to estimate the reliability of the regression coefficients (Hesterberg et al., 2003). In this resampling method, 1000 bootstrap samples are selected with resampling directly from the observations, after which the statistics for each bootstrap sample are calculated. Below we discuss the major model parameters (Table 2) and what these reveal about the geographies of Asia-Pacific tourism to Australia. 


\section{Results and discussion}

First, the adjusted determination coefficients are very high for all years. This implies that our model, although very straightforward in terms of its constituent parameters, is satisfactory: the independent variables jointly explain around $90 \%$ of the variation in tourism: the regression models estimate the Asia-Pacific tourism demand adequately, curbing the need for more complex travel demand models (Crouch et al., 1992). As expected, the elasticity of population is thereby close to 1 , thus effectively controlling for countries' different population sizes when reporting results in the remainder of this section.

Second, the value and evolution of the elasticities of GDP per capita reveals a number of interesting patterns. An unstandardized coefficient of GDP of approximately 2 in 1990 suggests that Asia-Pacific tourism to Australia used to be very income elastic: income growth in Asia-Pacific has thus been a major driver for the rising number of tourists. However, the value has been declining: In 1990, a rise of $1 \%$ in GDP per capita resulted in a $1.83 \%$ rise in Asia-Pacific holiday arrivals in Australia, while in 2010 elasticity declined to 1.53 . This implies that as the average income in the region increases, the demand for additional tourism slowly dampens. There are a number of different possible explanations for this trend. The uneven distribution of income in developing and newly industrialized countries may temper the translation of income growth directly to additional tourism demand. Thus, although the average GDP per capita has been growing quickly, and the growth in number of outbound Asia-Pacific tourists is impressive, these developments are generally confined to a small portion of each country's population. This is in turn deepened by the fact that income inequality in Asia-Pacific countries is on the rise (Ali, 2007). Another possible explanation would be the maturity of the Australian holiday market, where growth in tourism is increasingly driven by price reductions instead of income changes (Graham, 2006). That said, the coefficient remains larger than 1, implying that countries with higher average GDP per capita values continue to produce higher levels of tourists.

Third, distance has the largest elasticity, with a value above 3 for all periods. This strong, negative elasticity can above all be traced back to the fact that long-distance flights are usually more expensive than short-distance flights, accentuated by the commonly made observation that tourists tend to be more price-sensitive than business travelers (Brons et al., 2002). Furthermore, international air travel in the region is still principally regulated through bilateral air service agreements, which tends to boost airfares and thus hold down demand. Air transport liberalization between Australia and the other Asia-Pacific countries nonetheless progressed between 1990 and 2010. Although this has driven down travel costs, a large degree of regulation remains in place. Tourism Australia (2013) has acknowledged the fundamental role of increasing capacity on existing routes and the opening up of new routes to Australia to stimulate international tourism demand in its 'Tourism 2020' Plan, which sets out the key strategies for obtaining the Australian tourism industry's longer-term goals.

Despite the increased liberalization, however, the distance elasticity has actually increased towards 2010. This is probably due to the regional sensitivity for increasing fuel prices, which are taking up an increasingly large share of airlines' operating costs (Ringbeck et al., 2009). According to CAPA (2011), Asia-Pacific carriers were the most affected in this regard, which can be explained by the fact that the stage length in many Asia-Pacific airlines' networks is longer on average than those of North 
American and European operators, further illustrated by the fact that $40 \%$ of the long haul versions of the Boeing 777-300ER are now operated by Asia-Pacific airlines (CAPA 2013). This rise in fuel prices is commonly passed on to passengers as fuel surcharges; if this trend continues these extra costs can possibly impede growth in the demand for tourism to Australia.

Fourth, the beta coefficients of the different variables give us an insight into their respective individual influence on holiday demand. GDP per capita is the most important determinant of AsiaPacific tourism to Australia. This is in line with earlier findings of Lim (1997), who reveals income to be the most significant variable in a review of 100 published studies on empirical international tourism demand models. Specifically for tourism to Australia, Seetaram (2012) considers income in GDP per capita (in PPP) as the most important determinant of short-term visits. The smaller beta coefficient of distance reflects Ishutkina \& Hansman's (2009) findings that the influence of the distance is rather small compared to the other explanatory variables. However, the influence of distance rises towards 2010, while that of income decreases. This indicates that holiday travel to Australia becomes less income-dependent on increasing incomes (Forsyth, 2006), yet somewhat paradoxically more price-sensitive. 


\section{Implications}

Tourism is a major force integrating Asia-Pacific as a whole, and understanding the major factors driving it is therefore relevant for academics and policy-makers alike. In this research note, we have used insights from the travel demand literature to model the shifting geographies of Asia-Pacifc tourism to Australia. In this literature, higher incomes are generally associated with relatively higher demand for air transport, while larger distances -implying higher costs- are negatively linked to demand. The former is especially relevant in Asia-Pacific as many countries in the region have experienced strong overall economic growth and seen the rise of a middle class, the largest group of (new) tourists (cf. Robinson \& Goodman, 2013).

Our results allow us to draw a number of tentative conclusions regarding the challenges facing the Australian tourism market in Asia-Pacific, as well as the importance of air services liberalization and the dangers of increasing fuel prices for future growth.

Despite the fact that growth is to be expected in the immediate future (partly due to a further increase in Asia-Pacific countries' income), the decrease in income elasticity shows that the Australian tourism market is maturing. At some point, saturation of the market will be reached, and the tourism industry will encounter a situation where growth is no longer a given. Australia's experience with the Japanese market is an important example here; this market expanded rapidly to a high level, but it also declined rapidly again, and Japanese tourist numbers are continuing to decrease. Hence for the key-market of China it is important to recognize that the perceived organic growth (associated with the rise of income in that country) will not be ever lasting. Tourism Australia recognizes that although economic growth has been impressive in its Asian source markets (Korea, Hong Kong, Singapore, China, India, Indonesia, Malaysia and Viet Nam), an expected slower economic growth due to the current global economic situation (together with the maturing of the market) may worsen the outlook for tourism growth, particularly from China. The organization is trying to anticipate this through plans for campaigns that are focused on marketing Australia as a tourist destination across all Asian source countries, including cooperative marketing campaigns with airlines and industry.

However, marketing strategies alone are not enough, as we have shown that possible limits to growth are also obvious from the increase of the distance elasticity. Increasing fuel prices will pose a potential threat to future tourism growth. According to Airbus' (2010) Global Market Forecast 20102029 oil prices are expected to keep rising and reach the 2008 peak levels again by 2016, which will further drive air fares up. As increasing air transport liberalization may limit some of the damage caused by these costs, it is important that far-reaching liberalization is established between Australia and the Asia-Pacific countries. For instance, the bilateral air service agreement between Australia and China comprises free market entry and the possibility of flying to any destination, but currently still limits capacity. Although the capacity was increased by more than $50 \%$ under a memorandum of understanding agreed in 2011, this entire capacity was already reached by February 2013. Hence, an open skies agreement, without capacity restrictions, may be essential to sustain future growth in tourism demand. These benefits could also flow from liberalization efforts in the Asia-Pacific region as a whole. For example, ASEAN foresees a single aviation market by 2015, which will boost intraASEAN travel. Australia currently has several bilateral agreements with the constituting countries, but moving to an (open skies) agreement with ASEAN as a whole would equally benefit the tourism 
flows between Australian and ASEAN. One direct effect would be the introduction of more low-cost carriers on Australia-Asia-Pacific routes that could have a strong effect on air fares. 


\section{References}

Airbus (2010) Airbus Global Market Forecast 2010-2029. Retrieved December 13, 2010, from Website : http://www.avitrader.com/wp-content/uploads/2011/06/AirbusMarketOutlook2010-2029. pdf

Ali I. (2007) Inequality and the imperative for inclusive growth in Asia. Asian Development Review, 24 (2): 1-16.

Baldacchino G. (2006) Managing the hinterland beyond: Two ideal-type strategies of economic devel opment for small island territories. Asia Pacific Viewpoint, 47(1): 45-60.

Brons M., Pels E., Nijkamp P. \& Rietveld P. (2002) Price elasticities of demand for passenger air travel: A meta-analysis. Journal of Air Transport Management, 8(3): 165-175.

CAPA Consulting (2011) Mapping Australia's tourism aviation priorities (Stage 2). Retrieved Septembe r 30, 2011, from Website: http://www.tourism.australia.com/documents/Statistics/Statistics _Aviation_CAPA_Sept2011.pdf

CAPA Consulting (2013) Cathay Pacific 777X order ensures prompt re-fleeting while starting 777X sale s bonanza in Asia. Retrieved December 29, 2013, from Website: https://centreforaviation.co $\mathrm{m} /$ analysis/cathay-pacific-777x-order-ensures-prompt-re-fleeting-while-starting-777x-sales-b onanza-in-asia-146077

Crouch G. I. (1994) Price elasticities in international tourism. Journal of Hospitality \& Tourism Researc h, 17(3): 27-39.

Crouch G. I., Schultz L. \& Valerio P. (1992) Marketing international tourism to Australia: A regression analysis. Tourism management, 13(2): 196-208.

Efron B. (1979) Bootstrap methods: another look at the jackknife. The annals of Statistics, 7(1): 1-26.

Forsyth P. (2006) Martin Kunz memorial lecture. Tourism benefits and aviation policy. Journal of Air T ransport Management, 12(1): 3-13.

Gillen D. (2010) International air passenger transport in the future. In: OECD (ed.), The future for inter urban passenger transport: Bringing citizens closer together. Madrid: OECD.

Graham A. (2006) Have the major forces driving leisure airline traffic changed? Journal of Air Transpo rt Management, 12(1): 14-20.

Hesterberg T., Monaghan S., Moore D. S., Clipson A. \& Epstein R. (2003) Bootstrap methods and perm utation tests. Companion chapter 18 to the practice of business statistics, New York: W. H. Fr eeman and Company.

Ishutkina M. A. \& Hansman R. J. (2009) Analysis of the interaction between air transportation and ec onomic activity: A worldwide perspective Retrieved March 11, 2009, from Website: http://ds pace.mit.edu/bitstream/handle/1721.1/44957/Ishutkina_ICAT-2009-2.pdf?sequence=1

Kookana J., Pham T. D. \& Quinn T. (2014) Tourism's contribution to Australian economy,1997-98 to 2 012-13. Retrieved April 2014, from Website: http://tra.gov.au/documents/Tourisms_Contrib ution_1997-98_to_2012-13_FINAL_290414.pdf

Lim C. (1997) Review of international tourism demand models. Annals of Tourism Research, 24(4): 83 5-849.

Lim C. (1999) A meta-analytic review of international tourism demand. Journal of Travel Research, 37 (3): 273-284.

Mayer T. \& Zignago S. (2011) Notes on CEPII's distances measures: The GeoDist database Retrieved D ecember 2011, from Website: http://mpra.ub.uni-muenchen.de/36347/2/MPRA_paper_363 47.pdf

McElroy J. L. (2006) Small island tourist economies across the life cycle. Asia Pacific Viewpoint, 47(1): 61-77. 
McElroy J. L. \& Hamma P. E. (2010) SITEs revisited: Socioeconomic and demographic contours of smal I island tourist economies. Asia Pacific Viewpoint, 51(1): 36-46.

O'Connor K. \& Fuellhart K. (2014) The Asia Pacific region and Australian aviation. In: D. T. Duval (ed.), Air Transport in the Asia Pacific. Surrey: Ashgate.

Pearce D. (2001) Tourism. Asia Pacific Viewpoint, 42(1): 75-84.

Ringbeck J., Gautam A. \& Pietsch T. (2009) Endangered growth: How the price of oil challenges intern ational travel \& tourism growth. In: J. Blanke \& T. Chiesa (eds.), The Travel \& Tourism Compet itiveness Report 2009: Managing in a Time of Turbulence. Geneva, Switzerland: World Econo mic Forum.

Robinson R. \& Goodman D. (2013) The New Rich in Asia: economic development, social status and po litical consciousness. In: R. Robinson \& D. Goodman (eds.), The New Rich in Asia: Mobile Phon es, McDonald's and Middle Class Revolution. Abingdon: Routledge.

Scheyvens R. (2011) The challenge of sustainable tourism development in the Maldives: Understandi ng the social and political dimensions of sustainability. Asia Pacific Viewpoint, 52(2): 148-164.

Seetaram N. (2012) Immigration and international inbound tourism: Empirical evidence from Australi a. Tourism management, 33(6): 1535-1543.

Tourism Australia (2011) Tourism 2020: Whole government is working with industry to achieve Austr alia's tourism potential. Retrieved December 2011, from Website: http://www.tourism.austr alia.com/documents/Tourism_2020_overview.pdf

Tourism Australia (2013) Corporate Plan 2013-2016. Retrieved 2013, from Website: http://www.touri sm.australia.com/documents/corporate/tacp7579_corporateplan_13-16_web.pdf 
Table 1: Breakdown of holiday arrivals by country in 1990, 2000 and 2010. (Source: Australian Bureau of Statistics).

\begin{tabular}{|l|r|r|r|}
\hline & $\mathbf{1 9 9 0}$ & $\mathbf{2 0 0 0}$ & $\mathbf{2 0 1 0}$ \\
\hline Bangladesh & 120 & 850 & 980 \\
\hline Brunei & 930 & 3.080 & 3.090 \\
\hline Cambodia & 20 & 290 & 1.710 \\
\hline China & 3.700 & 40.660 & 204.710 \\
\hline Hong Kong & 26.130 & 83.300 & 69.270 \\
\hline India & 3.260 & 13.640 & 26.910 \\
\hline Indonesia & 17.930 & 44.220 & 54.620 \\
\hline Japan & 417.300 & 608.080 & 293.880 \\
\hline Laos & 10 & 290 & 420 \\
\hline Macau & 310 & 1.290 & 1.470 \\
\hline Malaysia & 22.290 & 90.420 & 123.130 \\
\hline Myanmar & 100 & 140 & 310 \\
\hline New Zealand & 181.290 & 355.930 & 466.450 \\
\hline Nepal & 120 & 200 & 450 \\
\hline Pakistan & 430 & 480 & 1.130 \\
\hline Philippines & 4.070 & 12.220 & 12.170 \\
\hline Singapore & 48.620 & 184.680 & 144.650 \\
\hline South Korea & 4.700 & 92.660 & 135.590 \\
\hline Sri Lanka & 1.140 & 2.300 & 4.380 \\
\hline Taiwan & 18.490 & 94.890 & 59.100 \\
\hline Thailand & 10.530 & 38.600 & 29.030 \\
\hline Vietnam & 160 & 1.740 & 7.510 \\
\hline & & & \\
\hline
\end{tabular}

Table 2: Results from the original and bootstrapped regression analysis of 1990, 2000 and 2010 (\# samples $=1000,{ }^{*} p<0.01$ )

\begin{tabular}{llccccccc}
\hline Year & Variables & Obs. coeff & Bias & Obs. beta & Obs.s.e. & Bootstrap s.e. & \multicolumn{2}{c}{$\begin{array}{c}\text { 95\%Cl } \\
\text { (bias-corrected) }\end{array}$} \\
\hline 1990 & GDP $_{\text {cap_origin }}{ }^{*}$ & 1.829 & 0.009 & 0.968 & 0.179 & 0.188 & 1.428 & 2.181 \\
& Pop $_{\text {origin }}{ }^{*}$ & 1.062 & -0.017 & 0.787 & 0.126 & 0.127 & 0.790 & 1.275 \\
& Distance* & -3.320 & 0.108 & -0.337 & 0.849 & 0.775 & -4.811 & -1.620 \\
& C & 4.504 & -0.726 & - & 8.010 & 7.028 & -11.141 & 18.312 \\
& Adj. R ${ }^{2}=0.878$ & & & & & & & \\
\hline 2000 & GDP $_{\text {cap_origin }}{ }^{*}$ & 1.779 & 0.009 & 0.975 & 0.126 & 0.103 & 1.529 & 1.944 \\
& Pop origin $^{*}$ & 0.959 & -0.008 & 0.759 & 0.087 & 0.111 & 0.725 & 1.164 \\
\hline
\end{tabular}




\begin{tabular}{lllllllll}
\hline & Distance* & -3.208 & -0.093 & -0.352 & 0.587 & 0.765 & -5.273 & -2.019 \\
C & 5.983 & 0.905 & - & 5.532 & 6.863 & -3.485 & 24.385 \\
& Adj. $\mathrm{R}^{2}=0.932$ & & & & & & & \\
\hline 2010 & GDP $_{\text {cap_origin }}{ }^{*}$ & 1.576 & 0.013 & 0.909 & 0.133 & 0.135 & 1.327 & 1.840 \\
& Pop $_{\text {origin }}{ }^{*}$ & 0.967 & -0.012 & 0.848 & 0.089 & 0.111 & 0.716 & 1.161 \\
& Distance* & -3.636 & 0.045 & -0.449 & 0.578 & 0.690 & -5.615 & -2.344 \\
& C & 10.614 & -0.280 & - & 5.453 & 5.725 & 0.221 & 26.681 \\
& Adj. $\mathrm{R}^{2}=0.932$ & & & & & & & \\
\hline
\end{tabular}

